\title{
Sobre la herencia del derecho matriarcal en Derecho natural y dignidad humana de Ernst Bloch y Casandra de Christa Wolf
}

María Belén Castano ${ }^{1}$

\section{Resumen:}

El objetivo del presente artículo es detenerse en el análisis que realiza Ernst Bloch en Derecho natural y dignidad humana (1961) sobre Bachofen, Gea-Themis y el derecho natural, con el fin de vincular la pertinencia de estas reflexiones en lo que respecta al abordaje del mito y el derecho materno en la novela Casandra de Christa Wolf (1983). Se examinará también cómo las propuestas de ambos autores se inscriben en una denuncia del patriarcado.

Palabras clave: derecho natural; matriarcado político; mito; Bachofen; patriarcado.

\section{On the inheritance of the matriarchal right in Natural Law and Human Dignity of Ernst Bloch and Cassandra of Christa Wolf}

\begin{abstract}
:
This paper looks into Ernst Bloch's analysis of Bachofen, Gea-Themis and Natural Law, as presented in Natural Law and Human Dignity (1961), with the aim of linking the relevance of these reflexions to Christa Wolf's approach to myth and maternal right in her novel Cassandra (1983). A further analysis will be offered on the way in which both author's proposals are engraved into a denunciation against patriarchy.
\end{abstract}

Key words: natural right; political matriarchy; myth; Bachofen; patriarchy.

\section{Introducción}

Las discusiones y controversias sobre la existencia histórica del matriarcado en sociedades antiguas fundadas en el predominio del poder femenino en las esferas como la política, la religión o el orden económico han sido numerosas. El estudio basado en la mitología griega del antropólogo Johann J. Bachofen (1815-1887) Das Mutterrecht (1861) representa un disparador para los debates modernos que surgieron alrededor de este tema. Bachofen se ocupa de la teorización de tres estadios por los que habría pasado la cultura europea: el hetáirico de la horda primitiva y la promiscuidad sexual sin propiedad, fundado en la

1 Becaria doctoral de Conicet, Universidad de Buenos Aires. E-mail: belcastano@gmail.com. 
igualdad y los estadios demetérico y apolínico, en los que el patriarcado y la organización social basada en la propiedad privada, la justicia racional, el sedentarismo y las instituciones de la familia y el matrimonio tienen lugar.

Este artículo se propone analizar las reflexiones que realiza Ernst Bloch en Derecho natural y dignidad humana (1961) sobre Bachofen, Gea-Themis y el derecho natural para compararlas con el abordaje del mito y el derecho materno presentes en la novela Casandra de Christa Wolf (1983). Nos proponemos reflexionar acerca de cómo ambos autores se pueden inscribir en el marco de una denuncia del patriarcado y la falta de existencia de un matriarcado político, aún en aquellos pueblos que hayan pasado en su historia por formas familiares matriarcales, con su veneración de la mujer y de los símbolos de la tierra. Esto da cuenta de cómo aquel desplazamiento de poder de las figuras femeninas forma parte de la conformación de un destino, de manera preliminar, de lo que luego a lo largo de tres mil años ha de ocurrir con las mujeres, esto es que ellas se conviertan en objetos ${ }^{2}$.

\section{Ernst Bloch y las críticas al derecho matriarcal del conservador Bachofen}

La teoría del derecho natural es entendida según Ernst Bloch como utopía jurídica, como un anhelo de justicia desde abajo para los humillados y ofendidos y está profundamente arraigada en su propia consideración del hombre como animal utópico, como constante creador de anticipaciones de un mundo mejor tal como explica Vedda (2011) al advertir que en los estudios de Bloch confluyen tanto las utopías sociales que tienen en vista la felicidad humana como los del derecho natural que se ocupan de la dignidad humana:

En el derecho natural encuentra el filósofo alemán la encarnación más genuina de este anhelo de justicia absoluta que no se contenta con un acomodamiento dentro de las circunstancias vigentes; este animus rebelde delata el lazo que une, más allá de sus divergencias innegables, al derecho natural con las utopías sociales, como dos tradiciones insurgentes de cuyo legado no podría deshacerse sin más el materialismo histórico. Entre ambas tradiciones advierte Bloch incluso una esencial complementariedad: las utopías sociales tienen en vista la felicidad humana; el derecho natural, la dignidad humana; las utopías soñaban circunstancias en que los hombres cesaban

\footnotetext{
${ }^{2}$ Cabe mencionar que la importancia que se le atribuye a la línea matrilineal o al derecho materno en los estudios feministas (WILLIAMS, 2011, p. 41) destaca el lugar privilegiado en el que se ubica el derecho materno en lo que respecta a las lecturas de la historia literaria femenina, cuyo análisis merece un estudio a parte y que no podemos abarcar en este trabajo.
} 
de vivir como seres agobiados y oprimidos; el derecho natural, circunstancias en que los seres humanos ya no se sienten humillados y ofendidos. En uno y otro caso, no se espera en una liberación desde arriba, por parte de un poderoso terrenal o supraterrenal que derrama sobre los débiles su benevolencia, sino en una emancipación desde abajo, que convierta a las propias víctimas en sujetos de la transformación social o jurídica (VEDDA, 2011, p. 3)

La fascinación que ejercieron en Bloch las propuestas del matriarcado de Bachofen no aparecen vinculadas con una realidad puntual confirmada por una historia política sino como anhelos utópicos de restos matriarcales, que se descubren solo en los mitos, en los que aparecen reflejos religiosos como causas de la constitución sexual del grupo y de sus transformaciones: la época primitiva hetaírica caracterizada por la libertad natural, la igualdad y la falta de propiedad, conforman las bases de un comunismo anticipado por Bachofen.

Resulta curioso que justo Ernst Bloch, un filósofo alemán cuyo largo recorrido intelectual fue siempre fiel a su compromiso con la construcción de una sociedad socialista se haya interesado por recuperar la herencia del derecho natural, idea que durante el siglo $\mathrm{XX}$ ha sido sostenida primordialmente por pensadores conservadores (SERRA, 2011, p. 11). No obstante, la reivindicación de Bloch del derecho natural está vinculada con su "forma de entender la filosofía y el lugar que le corresponde al Derecho como forma de regulación social” (SERRA, 2011, p. 11).

En el apartado "Bachofen, Gea-Themis y el derecho natural", Bloch advierte sobre los hallazgos de Lewis H. Morgan en relación a restos de constitución matriarcal en tribus indias que van mostrando la sucesión matrilineal como la más antigua en el Derecho de familia (BLOCH, 2011, p. 193).

Las críticas de Bloch a Bachofen son irónicas. Para Bloch, la mirada de Bachofen es alimentada por una idea de un viejo mundo cálido, matriarcal, está marcada por tonos románticos y antiempresariales y también románticos-feudales (BLOCH, 2011, p. 195). Bloch considera que Bachofen es tanto un mitólogo como un creyente en el mito y supone que esta "vinculación prehistórica a la madre provoca, en la misma medida de su amor, y a la vez, de su clarividencia erudita, falta de crítica y exageración" (BLOCH, 2011, p. 195). Bachofen agrupa sus descubrimientos en torno a tres ideas fundamentales, extraídas a partir de su interpretación de una suma de material de la literatura clásica:

Primero aparece "un estadio primitivo hetáirico (horda)", con el pantano como el lugar de la promiscuidad sexual, un estadio sin propiedad y con igualdad; a continuación aparece "un estadio medio demetérico", con tierra de cultivo y aldea, con propiedad, matrimonio, familia, sedentariedad, paz, divinidades de la tierra 
y un matriarcado bondadoso y sabio; surge después un "estadio final apolínico", con la polis como el lugar de residencia, dioses de la luz olímpico-uránicos, patriarcado y justicia racional (BLOCH, 2011, p. 196).

Bloch considera que aunque sea cierto que muchos pueblos hayan pasado en su historia por formas familiares matriarcales, con su veneración de la mujer y de los símbolos de la tierra y de Isis aquello "no coincide con un matriarcado político" (BLOCH, 2011, p. 197). Bloch sostiene que más allá de las reverencias a las mujeres, ya la fase agraria habría sido encabezada por hombres, es decir previamente a la sociedad patriarcal ganadera. Critica el análisis de Bachofen que supone que "la ginecocracia, unida a aquel derecho matriarcal, que pone en manos de la madre el poder en la familia y en el estado, es, en cambio de origen posterior y surge como reacción de la mujer contra la promiscuidad sexual, de la cual es ella la primera que aspira a liberarse" (BLOCH, 2011, p. 197). Bloch señala que el corazón del conservador Bachofen se encuentra del lado del matriarcado, mientras su cabeza del lado del patriarcado (BLOCH, 2011, p. 199). Y sostiene que es la "efusividad de su corazón" la que lo hace a Bachofen descubrir al matriarcado "en la forma de un culto religioso, de un culto a la tierra unido a la agricultura" en lugar de como una forma política (BLOCH, 2011, p. 199). Más aún, afirma que la ginecocracia "no se trata de ya de un matriarcado fingido, sino de una mitología profunda del culto materno para la religión, no para la política" (BLOCH, 2011, p. 200). Mientras Bloch se detiene en el concepto de mito arraigado en la concepción del derecho matriarcal de Bachofen, del que detalla el origen de la familia implantado por la mujer según tres estadios históricos organizativos de lo social, algo que permite justificar una fundación mítica del derecho, en la que el relato del patriarcado encuentra su contenido más armonioso, Benjamin en su ensayo "Johann Jacob Bachofen" hace hincapié en el vínculo entre dichas teorías y el fascismo, la psicología o el comunismo.

Benjamin se detiene en la particular elaboración de la prehistoria que realiza Bachofen, que rechaza todo lo que el sentido común del siglo XIX había imaginado sobre los orígenes de la religión y de la sociedad (BENJAMIN, 2010, p. 223). Destaca que las fuerzas irracionales que sustentan los estudios de Bachofen resultaron tentadoras tanto para los teóricos fascistas como para los pensadores marxistas por su evocación de una primera forma de sociedad comunista (BLOCH, 2011, p. 223). El análisis de Benjamin sobre Bachofen también critica su conservadurismo y aquel sentimiento ctónico ligado al culto materno y considera que sus ideas románticas sobre la era matriarcal se han expandido hacia territorios muy amplios (BLOCH, 2011, p. 230). Sostiene que la teoría sobre un orden familiar matriarcal en la Antigüedad, que habría precedido el dominio del 
pater familias, basado en un orden materno con diferentes bases jurídicas y sexuales de organización, en el que la madre podía acoger en su casa a uno o a varios maridos, ha sido explorada por varios historiados, filólogos y etnólogos como Vico, que plantea por primera vez esta cuestión como adivinatoria (BLOCH, 2011, p. 231). Para Benjamin, el debate no ha concluido y estos datos históricos han sido retomados en un sentido nuevo como indica el trabajo de Walter Lehmann, que ha estudiado los vestigios de una revolución cultural que ha acabado con el matriarcado (BLOCH, 2011, p. 231). También cita a Engels, que menciona aquella explicación de Bachofen religiosa como base de los cambios históricos en la situación social del hombre frente a la mujer: explicación sobre la que sustentaría el milagro religioso celebrado por la creencia de Bachofen de reemplazar al matriarcado por el patriarcado, algo que Benjamin considera un misticismo inadmisible fundado en "dotar a la religión como palanca decisiva de la historia” (BLOCH, 2011, p. 232). A partir de la crítica del carácter esotérico de las teorías de Bachofen, Benjamin identifica la apropiación que realiza el fascismo alemán, encarnada en la figura de Alfred Schuler, que inició a Ludwig Klages en la doctrina de Bachofen. También llama la atención sobre la fascinación que ejercieron para los teóricos socialistas y cita el ejemplo de Paul Lafargue, yerno de Karl Marx, cuyas ideas de Bachofen ligadas las bendiciones de la ginecocracia, la promiscuidad sexual y su cercanía con la religión de Dionisio y el régimen democrático despertaron interés por aproximarse a una sociedad más horizontal cuyo sentido de igualdad y justicia se acerca a una utopía venidera (BLOCH, 2011, p. 235). Benjamin hace hincapié en los ecos de la psicología de las teorías de Bachofen como es el caso de Erich Fromm que advierte las múltiples filiaciones con el fascismo de dichas teorías.

Tanto Bloch como Benjamin critican el carácter irracional de las teorías de Bachofen que vinculan el culto materno con la religión y la naturaleza, cuyo desplazamiento a ese lugar, si bien ellos no lo mencionan explícitamente, consideramos que implica necesariamente una justificación por parte del patriarcado que excluye históricamente al elemento de femenino del ámbito político a partir de fundamentos esotéricos; fundamentos que tal como sostiene Benjamin, también sirven de base al fascismo alemán y a ciertos ámbitos de las teorías socialistas y de la psicología, sobre los que no nos detendremos en este trabajo.

\section{Christa Wolf: la reescritura del mito de Casandra y las denuncias del patriarcado}

Casandra y Voraussetzungen einer Erzählung: Kassandra. Frankfurter Poetik-Vorlesungen (Prerrequisitos para una narración: Kassandra. Conferencias sobre poética en Frankfurt) fueron publicados en 
1983. En dichos ensayos Wolf detalla el proceso de elaboración de la novela Casandra y hace alusión directamente a su vínculo con el contexto político de la época y las amenazas nucleares que enfrentaban a los bloques socialistas y capitalistas.

Antes había publicado Moskauer Novelle (1961) (Novela de Moscú), con la que le otorgan el Kunstpreis der Stadt Halle; con Der geteilte Himmel (1963) (El cielo dividido) recibe el Premio Heinrich Mann; luego publica Nachdenken über Christa T. (Noticias sobre Christa T.) (1968); Kindheitsmuster (Muestra de infancia) (1976) y Kein Ort. Nirgends (1979) (En ningún lugar, en parte alguna). Cuando en 1980 recibe el Premio Büchner, en el que anticipa que la vida de la hija real griega había sido un relato clave para ella, Wolf no se refería con eso ni a los paralelos entre las figuras del mito y personas vivas, ni a una identidad entre Casandra y la autora, más bien se refería a asociaciones que se relacionan con el mito mismo (HÖRNIGK, 1989, p. 232). En el verano de 1980, Wolf viaja a Grecia junto a su marido con la Orestíada de Esquilo en su equipaje y luego va a dar las clases teóricas Voraussetzungen einer Erzählung: Kassandra en la primavera de 1982 en la Universidad de Frankfurt invitada como docente de poética. La tradición de estas clases teóricas la inició en el verano de 1960 Ingeborg Bachmann (HÖRNIGK, 1989, p. 232)

La novela está estructurada como un monólogo en el que la protagonista relata en primera persona los episodios anteriores y posteriores a la guerra de Troya que la llevan a su condena de muerte.

Casandra es la hija más bella de Príamo y Hécuba, reyes de Troya, que de joven recibe el don de la profecía del dios Apolo a cambio de entregarse a este, pero como no cumple esa promesa, la venganza del dios es que ella continuará profetizando pero nadie creerá jamás en sus pronósticos y su mayor desgracia será el vaticino de la derrota de la guerra de Troya, luego de la que es entregada a Agamenón como botín de guerra y es conducida al palacio de Micenas donde encontrará la muerte en manos de Clitemenestra. A medida que avanza la narración, Casandra sufre un proceso de pérdida de fe en los dioses y realiza un cuestionamiento de la religión, detrás de cuyo discurso permeado por promesas y sacrificios, descubre que se esconden intereses bélicos y económicos. Casandra puede desenmascarar relatos religiosos, no cuestionados por sus pares, considerados como datos objetivos, desde un lugar subjetivo: el de su propia voz. "¿Por qué quise sin falta el don de profecía? Hablar con mi propia voz: lo máximo. No quise más, ninguna otra cosa.” (WOLF, 1986, p. 12). Ella misma se define como una incrédula y considera que el género humano está solo y que no hay dioses que la puedan mirar, detener, ni juzgar más allá de la muerte:

Por qué no me permito simplemente esa recaída en la criatura. Qué me detiene. Quién me ve aún. ¿Es que yo, la incrédula, sigo 
estando en el centro de la mirada de un dios, lo mismo que de niña, de muchacha, de sacerdotisa? ¿Es que no termina nunca? (WOLF, 1986, p. 33)

Aquí es posible evidenciar una alusión al deseo de ser fiel a sí misma y una reflexión sobre los fines no egoístas de seguir la propia vocación, ya que, para ella, eso permite ser más útil en una sociedad a los demás. Es por ello que resulta sugestivo el llamado de la protagonista de la novela a seguir el camino de la propia voz para poder ser útil a los demás, una reflexión que le devuelve armonía a la comunidad y a sus individuos particulares, algo que la tradición crítica señala como el carácter utopista de Wolf y que es posible vincular con lo que Bloch rescata del derecho materno en Bachofen. La voluntad de Casandra de quebrar los designios de los dioses se declara por primera vez cuando Apolo, el dios de los adivinos, se le aparece en el sueño en el que le otorga el don de la profecía y ella lo rechaza cuando Apolo intenta acercarse a ella como hombre y luego como un lobo, rodeado de ratones y la escupe furiosamente al no poder forzarla: un sueño que la protagonista le cuenta a su madre y a Marpesa. El rechazo a ser poseída a la fuerza por los hombres es el motivo principal que la lleva a querer convertirse en sacerdotisa, algo que decide luego del episodio del recinto del templo de Atenea cuando la llevan junto a otros jóvenes a ser elegida por hombres que iban a desflorarlas: "Conocía el vacío desde pequeña. Sentí dos clases de vergüenza: la de ser elegida y la de quedarme allí. Sí, sería sacerdotisa, al precio que fuera" (WOLF, 1986, p. 26).

El cuestionamiento al don de la profecía por parte de Casandra está asociado con un proceso de autoconocimiento a través del que ella descubre la existencia oprimida que llevaba, con una vida determinada por los dioses y las exigencias del palacio, acontecimientos que conducían a otros y finalmente a la guerra; es allí cuando considera que el don de la profecía la abrumaba y que en realidad estaba frente a una ceguera: "no veía nada. Abrumada por el don de profecía, era ciega" (WOLF, 1986, p. 38). La contradicción de Casandra en su deseo de servir a los dioses se evidencia luego de su recaída de salud cuando estalla la guerra y ella vuelve a realizar tareas como sacerdotisa, una etapa que más adelante considera teñida por una ceguera parcial. Es allí cuando sostiene que ver de repente la hubiera destruido y realiza una reflexión que está ligada a la capacidad paulatina de descubrimiento de su persona y de sus propias creencias, y al desmantelamiento de los velos de la religión y la lógica del palacio. Otra ocasión en la que Casandra da cuenta de su falta de credibilidad en la religión es cuando se suicida su hermano Esaco en los acantilados luego de la muerte de su esposa en un parto. En el palacio, Calcante, interprete del oráculo, sostiene que el joven Esaco se había convertido en un pájaro según una concesión de sus deseos más íntimos por obra de la diosa 
Artemis: "aunque hubiera podido creer, pero no lo creía, que mi hermano Esaco era un pájaro" (WOLF, 1986, p. 50). Casandra desprecia los sacrificios humanos realizados en nombre de la religión, algo que se manifiesta explícitamente en la conversación que tiene con Agamenón, que había hecho sacrificar a su propia joven hija Ifigenia, antes de la travesía de su flota en el altar de la diosa Artemis: una exigencia de Calcante para que tuvieran vientos favorables.

La Casandra de Wolf carga con la pena de haber intentado advertir a través de sus profecías sobre la falta de sentido y los peligros de autodestrucción que comportan dejarse llevar por las conductas bélicas y nadie le cree. Ella considera que las decisiones relacionadas con la guerra, la violencia, el honor, el orgullo y los héroes forman parte del patriarcado y podrían ser diferentes si hubiesen sido tomadas por sujetos femeninos. El pesimismo de la narración no recae en la creencia fundada a partir de la idea del progreso de la historia, sino más bien lo contrario, ya que alude a la condena del género humano a repetir los mismos errores y a un alternarse de batallas y victorias de los mismos sujetos: los vencedores pertenecientes a la clase dominante. En el final del monólogo, Casandra explica el motivo por el que había decidido no partir junto a Eneas: se niega a seguirlo para no fijarse en la repetición de los errores a los que, para ella, él se habría entregado. Su mensaje pacifista implica un llamado en contra de la aniquilación del género humano y propone despreciar el concepto de héroe de batalla y dejar de querer vencer para poder perdurar:

Acaso esté libre para expresarme en el cautiverio. Queridos enemigos. Quién soy yo para no ver en vosotros más que a los vencedores, y no también a los que vivirán. A los que tendrán que vivir, para que lo que llamamos vida continúe. Esos pobres vencedores tienen que seguir viviendo por todos los que han matado. Les digo: Si pudierais dejar de vencer, esa ciudad vuestra perduraría (WOLF, 1986, p. 138).

La tradición crítica y la autora misma en los ensayos Voraussetzungen einer Erzählung: Kassandra se han ocupado de analizar el vínculo entre las figuras de los vencedores con el patriarcado y el mundo occidental capitalista. Wolf ha puesto la lupa en su identificación con el género femenino del lado de los oprimidos, que adhiere a la búsqueda de otro tipo de sociedad utópica, opuesta a la del uso y abuso de la técnica y la explotación de la naturaleza y del hombre del capitalismo. Dicha comunidad o alternativa utópica, encarnada en la narración en las mujeres que habitan las cuevas de Escamandro estaría vinculada con la solidaridad, la comunión con la tierra y la capacidad de expresarse y de mantener vínculos auténticos entre ellas. Para Kuhn (1988, p. 78), el proyecto de Casandra explora cómo la exclusión sistemática de lo femenino por parte del patriarcado ha modelado la presente situación política catastrófica. 
Algo que Hilzinger (1986, p. 131 y p. 132.) considera un emprendimiento que demanda una historiografía desde abajo y una poética de la resistencia que es llevada adelante por las mujeres que desde este cambio histórico se encuentran entre las oprimidas y las excluidas. Hörnigk (1989, p. 244) señala que Casandra vive en un agujero de los tiempos, en el umbral del cambio social del matriarcado al patriarcado y que ella se vuelve testigo de un cambio de valores, las mujeres que se juntan en las montañas, en un modelo utópico, que huyen de los sucesos de guerra y practican un modo de vida alternativo transmiten el asomo de una esperanza; pero de la protagonista de la novela se desprende que como instrucción para la acción no quiere, ni puede hacer funcionar ese modelo (íd.). A pesar de que Casandra puede mejorar su estado de ánimo en el entorno pacífico, no es capaz de identificarse con la religiosidad ingenua del culto de Cibeles.

Muchos son los críticos que consideran que esta obra está ambientada en un contexto de transición de un pasado matriarcal hacia un patriarcado, con la consecuente nostalgia por aquel tiempo extinguido en el que las mujeres eran protagonistas de la civilización y de la toma de decisiones. Este es el caso de Rainer Gerdzen y Klaus Wöhler (1991, p. 10), que sostienen que la novela está ubicada exactamente en ese quiebre en la situación de recambio del matriarcado al patriarcado, entre la edad dorada y el apocalipsis. Otros como Emmerich (1989, p. 354 ) critican la tematización del matriarcado por parte de Wolf, por el hecho de que consideran que este tema es tratado por la autora de manera liviana y como si fuera un hecho históricamente comprobado; Hörnigk (1989, p. 237) declara que Wolf le otorga referencias sociales e históricas a la novela, y que realiza una psicologización desde la perspectiva femenina de los perdedores, en la que ubica los eventos de Casandra cercanos a un matriarcado prehistórico en caída, en la era patriarcal heroica que estaba iniciando. La novedad que destaca Kuhn sobre Wolf respecto al marxismo es que en su interpretación, la alienación no sería una consecuencia de la industrialización, sino que sus raíces deben ser buscadas en la cuna de la civilización occidental (HÖRNIGK, 1989, p. 185). Y recalca el hecho de que, para Wolf, la alienación se origina cuando la cultura patriarcal desplaza a la matriarcal, con la introducción de un pensamiento jerárquico, y se prohíbe la participación de las mujeres en la esfera pública, cuando las estructuras sociales se hacen rígidas y los seres humanos son tratados como medios para un fin (HÖRNIGK, 1989, p. 185).

\section{Conclusiones}

¿Cómo es posible encontrar en la reescritura del mito de Casandra una afinidad con las reflexiones que realiza Bloch sobre el Derecho matriarcal analizado por Bachofen? En primer lugar, es posible rastrear 
una coincidencia con Bloch en la reflexión sobre la dificultad en la obra de dar cuenta acerca de la existencia de un matriarcado propiamente político en la Antigüedad. La voz de Casandra es silenciada paulatinamente en la novela de Wolf, pero también es asociada con la locura. Esto implica una degradación de su voz como sujeto femenino y una crítica al patriarcado. En segundo lugar, las consideraciones de Bloch sobre las reflexiones de Bachofen que dan cuenta de la asociación entre un mundo femenino ligado a la tierra, a la fertilidad y más bien a la religión, excluido de cualquier ámbito político son cuestiones que la novela de Wolf problematiza. Como mencionamos antes, la protagonista cuestiona por sobre todas las cosas la credibilidad de la religión en general y su utilización como pretexto de disputas de poder y deseos de aniquilación, pero también postula la dificultad de los sujetos femeninos para ocupar puestos de poder y manifiesta su deseo de haber nacido hombre y de cambiar su sexo. Casandra anhela ser un hombre como su hermano gemelo Héleno, al que envidia al comparar la función menor que tenían sus tareas de sacerdotisa con respecto a las de él como arúspice. Casandra sostiene que toda la frivolidad le había sido atribuida a Héleno y considera que toda la melancolía la tenía ella. Allí es posible identificar un vínculo entre la actitud crítica de la protagonista y la melancolía, que es opuesta al carácter superficial y a las reflexiones ingenuas de su hermano: "Héleno no era adivino. No tenía el don, necesitaba el ritual. Toda la frivolidad que quizá nos había estado destinada a los dos la había recibido él. Toda la melancolía la tenía yo. Cómo deseaba estar en su lugar" (HÖRNIGK, 1989, p. 40). También alude a la forma y al tono diferente en el que ella hubiese hablado en su lugar, no solamente de temas convencionales como los que él trataba con comunicados débiles sobre lluvias, soles, prosperidad y ruina de cosechas o crianza de niños y animales (HÖRNIGK, 1989, p. 40). Al mismo tiempo, en este mismo apartado es posible identificar lo que serían aquellos vestigios de un pasado matriarcal cuando se habla de las ropas de mujer que su hermano Héleno debía usar para rituales religiosos, como si ese oficio podría haber estado, en el pasado, reservado solo para las mujeres, algo que también sostiene Stein (1994, p. 175 y p. 176).

Nuestra lectura, en consonancia con el análisis de Bloch sobre los estudios de Bachofen, no identifica en la novela Casandra una fase de transición clara de un matriarcado al patriarcado ya que no hay rastros en la novela de un matriarcado estrictamente político que se habría extinguido. Creemos que Wolf deja abierto el interrogante sobre esta posibilidad y que la narración pone a la luz un desplazamiento de poder de las mujeres que se sitúan en los márgenes de las sociedad patriarcal en dos espacios enfrentados: por un lado, el de las mujeres de Pentesilea identificadas con una participación guerrera femenina que está en contra 
de los hombres, y por otro lado, la vida pacífica y aislada de la comunidad de las cuevas de Escamandros. Es posible pensar que lo que la narración revindica, como dijimos antes, es el poder de la palabra para instruir y prevenir a las mujeres de futuras generaciones sobre la catástrofe que comporta la exclusión de las mujeres de los ámbitos de poder y de las decisiones políticas. Aquella transmisión escrita u oral de su experiencia es la que Casandra anhela cuando implora que le manden un escriba o alguien capaz de transmitir su mensaje a su hija (p. 99) y a las hijas de su hija, ya que lo que ella tiene para decir lo considera más importante que sufrir un encierro en vida.

Más allá de la identificación de rastros matriarcales que señalamos en la pertenencia al género femenino con la que, en la novela, se caracteriza a los atuendos de los sacerdotes, no es posible identificar un pasado de organización política en la que las mujeres hubieran estado al mando. En todo caso, estos vestigios dan cuenta de un posible desplazamiento de poder en el ámbito religioso, pero no en el político. Esto coincide con la consideración de Bloch, antes mencionada, sobre la dificultad de encontrar huellas de un matriarcado político en muchos pueblos que hayan pasado en su historia por formas familiares matriarcales ligadas a la veneración de la mujer y de los símbolos de la tierra. En la novela de Christa Wolf justamente es posible identificar una denuncia ligada a la falta de lugar de la mujer en el ámbito público y político, ya que hace hincapié en los abusos perpetuados por el patriarcado que relegan a la mujer al ámbito doméstico desde la época en la que está ambientado el mito -que reescribe en su novela- hasta la Modernidad.

\section{Referencias bibliográficas}

BENJAMIN, Walter. Johann Jacob Bachofen. En: - Obras. Libro

II/ v. 1. Estudios metafísicos y de filosofía de la historia. Edición de Rolf Tiedemann y Hermann Schweppenhäuse con la colaboración de Theodor Adorno y Gershom Scholem. Edición española al cuidado de Juan Barja, Félix Duque y Fernando Guerrero. Madrid: Abada, 2010, pp. 222-37.

BLOCH, Ernst. Bachofen, Gea-Themis y el Derecho natural. En:

Derecho natural y dignidad humana. Edición, estudio preliminar y notas de Francisco Serra. Traducción de Felipe González Vicén. Madrid: Dykinson, 2011, pp. 193-212.

EMMERICH, Wolfgang. Kleine Literaturgeschichte der DDR. Darmstadt / Neuwied: Luchterhand, 1984 (Leipzig: Kiepenheuer, 1996, reed. ampliada).

GERDZEN, Rainer; WÖHLER, Klaus. Matriarchat und Patriarchat in Christa Wolfs" Kassandra". Würzburg: Königshausen \& Neumann, 1991. HILZINGER, Sonja. Christa Wolf. Stuttgart: Metzler, 1986. 
HÖRNIGK Therese. Schriftsteller der Gegenwart. Berlin: Volk und Wissen, 1989.

KUHN, Anna K. Christa Wolf's utopian vision from Marxism to feminism. Cambridge: Cambridge University Press, 1988.

SERRA, Francisco. Estudio preliminar. El derecho natural en el pensamiento de Ernst Bloch. En: Derecho natural y dignidad humana. Edición, estudio preliminar y notas de Francisco Serra. Traducción de Felipe González Vicén. Madrid: Dykinson, 2011, pp. 11-42.

STEIN, Katerina. "Helden der Ausweglosigkeit: Christa Wolf's Kassandra". En: Wallace, Ian. Christa Wolf in perspective. Atlanta: Rodopi, 1994, pp. $173-85$.

WILLIAMS, Linda R. Happy families? Feminist reproduction and matrilineal thought. En: EAGLETON, Mary (Ed.). Feminist literary theory. A reader. Malaysia: 2011, pp. 41-5.

VEDDA, Miguel. Derechos humanos y justicia desde abajo. Releyendo Derecho natural y dignidad humana, de Ernst Bloch. Actas del IV Seminario Internacional Políticas de la Memoria Ampliación del campo de los derechos humanos. Memoria y perspectivas, 2011.

WOLF, Christa. Casandra. Madrid: Alfaguara, 1986.

. Voraussetzungen einer Erzählung: Kassandra. Berlín: Surkamp, 2008.

Como citar:

CASTANO, María Belén. Sobre la herencia del derecho matriarcal en Derecho natural y dignidad humana de Ernst Bloch y Casandra de Christa Wolf. Verinotio - Revista on-line de Filosofia e Ciências Humanas, Rio das Ostras, v. 25, n. 1, pp. 240-51, abr. 2019.

Data de envio: 16 ago. 2018

Data de aceite: 23 out. 2018 